\title{
Fuzzy Logic-Based Autonomous Controller for Electric Vehicles Charging under Different Conditions in Residential Distribution Systems
}

\author{
Samy Faddel, Ahmed A. S. Mohamed and Osama Mohammed \\ Energy Systems Research Laboratory, Florida International University, Miami, Florida USA \\ mohammed@fiu.edu
}

\begin{abstract}
Integrating a fleet of electric vehicles (EVs) in the distribution system without a communication infrastructure exhibits several issues that need to be handled by electric utilities. Robust autonomous controllers are crucial in this case to manage the charging operation without violating the grid standard limits. This paper proposes a communication-free autonomous charging controller for EVs in distribution systems. The controller is based on fuzzy logic considering both the system voltage profile and the EV's battery state of charge (SOC). The fuzzy inference system is designed to avoid under voltage issues in the grid, flatten the system loading profile and accomplish fair charging among different EVs connected to the system. An 18-bus distribution system driven by the proposed controller was implemented in a simulation environment. The proposed controller performance was investigated under different distribution system operating conditions such as different loading, different levels of EV penetration, system reconfiguration as well as with distributed generation. In all cases, the controller demonstrated faster and better charging performance without violating the standard voltage limits compared to other research reported in the literature.
\end{abstract}

Index Terms - Autonomous, Distributed generation, Distribution systems, Electric Vehicles (EV), Fuzzy logic control (FLC).

\section{Introduction}

With the desire for clean and efficient transportation coupled with advances in the battery and power electronics technologies, an increased use of plug-in EVs and hybrid EV in the market is occurring. EVs are expected to dominate the vehicle market in the near future [1]. Although EVs have numerous positive 
advantages, such as reduced local emissions [2], [3], and less dependence on fossil fuel through the integration of renewable energy resources [4], unmanaged charging can negatively affect the utility grid. Many studies showed that without any management over the process of EV charging, failures or unacceptable power supply quality issues will occur in the grid frequently even with a small EV penetration rate. The resulting impacts, on the low voltage distribution grid range from transformers overloading [5] to line losses [6], low voltages [7]. Therefore, charging management is a major issue for successful integration of EVs in the distribution network where the vast majority of the impacts will occur since most of the EVs will be connected to it.

Many techniques have been proposed in the literature to control EV charging and prevent these negative impacts on the utility grid. These methods can be classified into three main categories: centralized, decentralized and autonomous charging control. The majority of the proposed control strategies were focused on centralized control coordinated with utility operator. In [8], the centralized control strategy allowed balancing single-phase loads connected to the microgrid by adapting the charging rates of the EV storage devices. EVs, as energy storage, was used in [9] for frequency regulation. Methods to minimize distribution feeder losses were considered in [6], [10]. These studies revealed that feeder load profile can be flattened and voltage violations can be reduced. Centralized controllers generally depend on one large system operator that manages the whole process after collecting all the required data. If the main link with the operator is lost, the whole system will be badly affected and this is a major drawback with centralized controllers. Other techniques have focused on decentralized control, which has the advantages of reduced communications infrastructure and less computational burden.

In [11], control of energy flow between EVs and the grid has been demonstrated using fuzzy logic controllers (FLC) mainly for voltage compensation and peak shaving. The proposed technique in [11] requires heavy computation and assumes that all EVs in a certain area will charge from a certain charging station and the charging station will work most likely as an aggregator. In [12], the fuzzy logic controller 
was used to manage the charging of large pool of EVs for load flatting at the primary distribution level. The charging stations are communicating with an aggregator at the distribution system substation to decide on the total power to be exchanged with the grid. In [13], a decentralized charging algorithm was formulated by emulating the charging pattern identified through linear programming (LP) optimization solutions. This latter method achieved a cost that is close to the one resulted from centralized optimal control using LP. Another decentralized methodology focuses on managing all of the charging within a parking lot with its own maximum charge rate [14]. The scheduling problem formulation for the EVs charging was investigated in [15]. The objective function was to impose a generalized notion of valley filling.

All the above mentioned methods depend on some kind of communication. This communication can be done with the system operator for the case of the utility or with charging station aggregator. To reduce the requirement for large investment on communication infrastructure, autonomous charging control was developed. It mainly relies on some sort of local input at the point of connection which lessens the need for communication infrastructure. Fuzzy logic was used in [16] and [17] to adapt a PID controller to control the voltage under different loading conditions for a standalone PV system. Limited work was performed to consider communication-free EV charging which permits independent charge control. An autonomous control scheme for multiple EVs in the distribution networks was proposed in [18]. The proposed method focused on using the EV as energy storage during transition from grid connected mode to islanded mode of operation. In [19], an autonomous approach for real time management of local voltage and thermal constraints for distributed generation (DG), utilizing the concept of sensitivity analysis, was considered. It controls generator active and reactive power output to overcome voltage and thermal issues near the point of connection. In [20] and [21], the authors have proposed a voltage-based control scheme for charging EVs. This control, though requires no real-time communication, effectively coordinates charging among the EVs connected to the distribution nodes in a good manner. However, it 
requires changing the reference points of the controllers with each seasonal variation. In addition, EVs at the upstream bus charge relatively faster than the downstream ones. In [22] and [23], a technique for EV charge management with variable gain was introduced. Although the method showed a good performance without the need for changing the controllers`reference points, the charging rate slowed down. Also, the controller showed a conservative behavior when it comes to increasing the charging rate for the upstream bus when there is a room to charge more.

Aside from the existing work in the literature, this paper proposes an autonomous fuzzy logic controller to manage the charging of EVs that are connected to different houses in the distribution system. The controller is communication-free which reduces the investment cost needed for a communication infrastructure. It ensures that the voltages at different houses will not exceeds the standard limits $( \pm 5 \%$ as reported by ANSI C84.1-2006 standard). In addition, the controller uses the idea of fair charging to manage a near equal charging rate between different EVs at different houses in the system. An 18 bus distribution system including the primary and secondary parts driven by the proposed controller is implemented and tested in simulation environment. Extensive simulations were performed to test and verify the effectiveness of the proposed controller under different operating conditions. These tests include the controller performance under different penetration levels of EVs, different loading conditions and system reconfigurations, in presence of capacitor banks, and in the presence of distributed generation units. Also, the sensitivity of the controller to errors in state of charge estimation is tested. The proposed controller shows better performance compared with other techniques reported in the literature. It does not violate the voltage standard, shaves the peak loading, can accommodate large penetration of EVs, manages fair charging among different EVs, takes the advantage of any existing room for more charging and performs well in the presence of voltage control units and distributed generation.

\section{Testing System Description}

The three phase unbalanced configuration under study for testing the effect of EV charging is shown in 
Fig. 1. It is a primary distribution network with 18 buses. The operating voltage at the primary distribution is $12.46 \mathrm{kV}$ line-to-line. The conductors are organized in a symmetric geometry with a geometric mean spacing of $4.69 \mathrm{ft}$. Every load bus has 20 houses connected to each secondary phase. The parameters of the distribution system are found in Table 1. This structure was previously used in [24], [25]. The secondary distribution infrastructure, shown in Fig. 2, is modeled based on the field site configuration of Utility E in [26], which has several splice boxes as well as houses connected directly to the distribution transformer through triplex lines at a nominal service voltage of $240 \mathrm{~V}$. The parameters of the secondary distribution network are given in Table 2. A small resistance is also added to model the EV charging cable.

The applied load profile is based on historical Residential High Winter Ratio (ResHiWR) load profiles found in the ERCOT system with five minutes resolution [21].To the ERCOT loading profiles, Gaussian distributed random noise is added to introduce changes in the individual use. One EV for each two houses in the system was adopted. This means that for each two houses, one of them will contain an EV and the other will not [20]-[23]. Therefore, each phase of the secondary transformer has 10 EVs and the total number of EVs connected to the network is 510. This level was chosen because it represents a large scale set of EVs in the distribution network and can cause significant issues with EV charging .The $\mathrm{EV}$ s on each bus are labeled with numbers from one to thirty, i.e. $\mathrm{EV}_{1}, \mathrm{EV}_{2}, \ldots, \mathrm{EV}_{30}$. This applies to each of the load buses $(2-18)$. The maximum charging rate for each $\mathrm{EV}$ is $6.6 \mathrm{~kW}$ and the full capacity for EV battery is $24 \mathrm{kWh}$ which emulates the 2013 Nissan Leaf [27]. For simplicity, the initial state of charge (SOC) for the EVs is set to be around 40\%. Also, it is assumed that the network under study is operating under the time-of-use (TOU) tariff structure where a lower tariff is applied from 6 pm to $6 \mathrm{am}$. To take this into account and the fact that the EV plug-in time is expected to be random, the plug in time of EVs was assumed to follow a Gaussian distribution centered at $8 \mathrm{pm}$ and with a standard deviation of one hour. The results of the voltages at the primary load buses are normalized by the nominal system 
voltage for a $12470 \mathrm{Y} / 7200-\mathrm{V}$ rating while the voltages at the point of connection (POC) at the different houses were normalized by the nominal utilization voltage for a 240/120-V rating. Since the nominal utilization voltage is only $230 / 115-\mathrm{V}$ for a $240 / 120-\mathrm{V}$ rating, the POCs may have higher per unit voltage values than those of the buses.

The system and the controllers are implemented in Matlab/Simulink. Figure 3 shows a basic schematic diagram of the simulation setup designed in the Simulink environment. Three phase power flow analysis is performed to calculate the voltages at different charging points of the system. The load flow uses forward-backward sweeping algorithm which is commonly used for radial distribution systems. The inputs to the load flow are the total power at points of charging. Here, $n$ represents the bus number, where $n \in[2,18], p$ is the phase number, where $p \in[1,3]$, and $i$ is the house number, where $i \in[1,20]$. The controller decides on the power draw, $\operatorname{PD}(\mathrm{n}, \mathrm{p}, \mathrm{i})$, which is added to the non-EV load at the house, and the total power, $\mathrm{P}(\mathrm{n}, \mathrm{p}, \mathrm{i})$ is used as an input for the next power flow update.

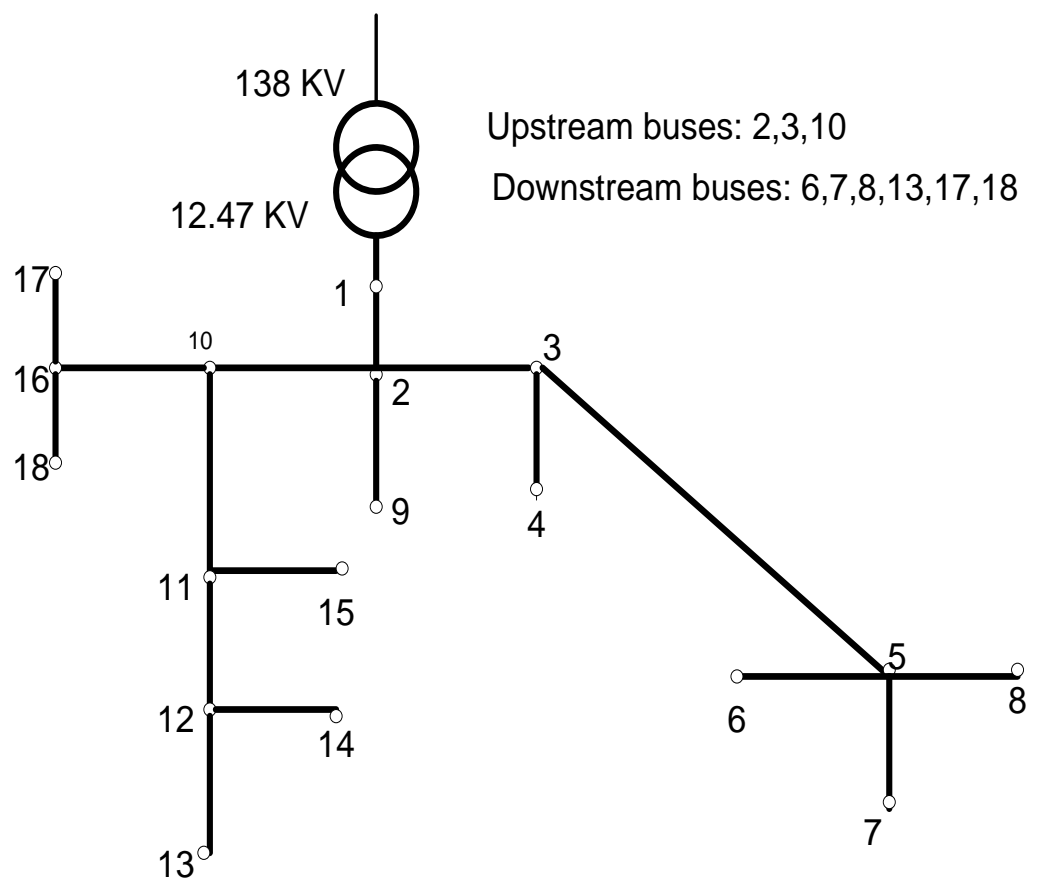

Fig. 1: The primary distribution feeder test network 


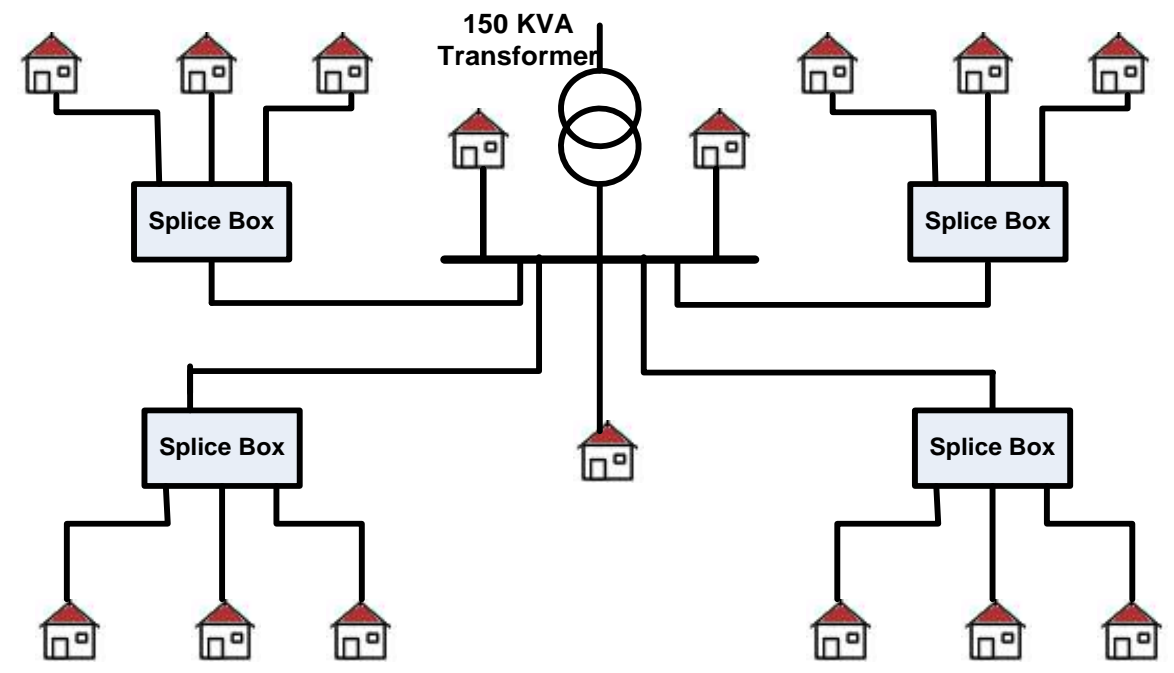

Fig. 2: Secondary distribution network topology

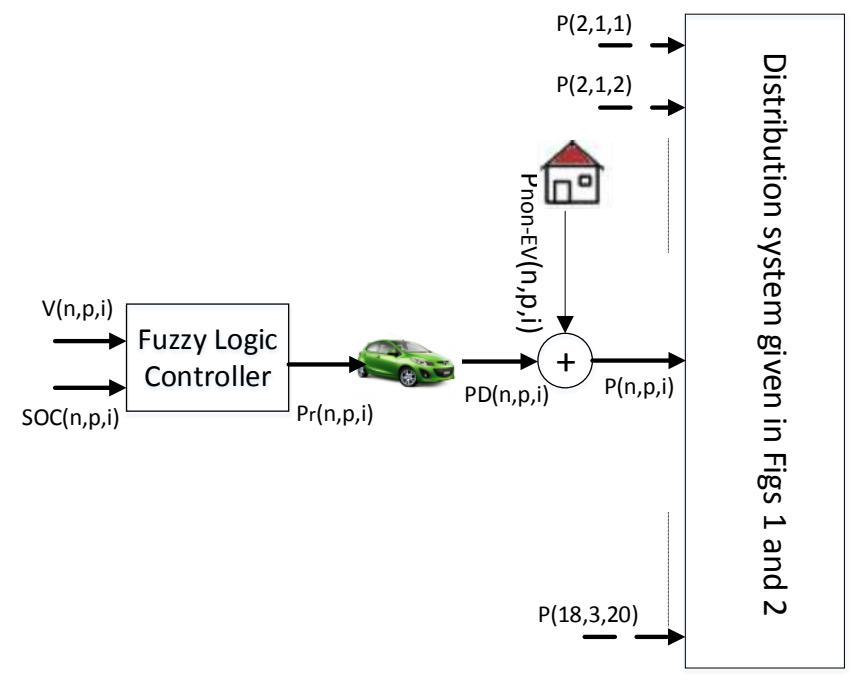

Fig. 3 Simulation setup in Matlab

Table 1 Distribution System Parameters

\begin{tabular}{|c|c|}
\hline Phase Conductor & ACSR 2 \\
\hline Neutral Conductor & ACSR 4 \\
\hline Max Amps & 180 \\
\hline Houses & 1020 \\
\hline
\end{tabular}


Table 2 Secondary Network Parameters

\begin{tabular}{|c|c|}
\hline Parameter & Value \\
\hline EV Charger Penetration & $50 \%$ \\
\hline Distribution Service Transformer & $150 \mathrm{kVA}, \quad 350 \mathrm{Al}, 4 / 0 \mathrm{Al}$ Neutral \\
\hline Secondary Conductor (transformer to splice box) & $\# 2 \mathrm{Al}$ \\
\hline Service Conductor (to the houses) & 20 \\
\hline No. of customers & \\
\hline
\end{tabular}

\section{The Proposed Fuzzy Logic Charging Controller}

The EV charger converts the AC current coming from the grid to an adjustable DC current in order to charge the batteries. EV's battery charging typically happens in the constant current region of the Liion battery characteristics. Therefore, from the grid point of view, the EV behaves as a current source [28]. In this paper, the EV is modeled as an adjustable negative DC current source (acts as a load) where the power drawn is based on the controller. The SOC estimation is done using ampere-hour counting method because it permits the accurate calculation of changes in the SOC. The ampere hour (Ah) counting method mainly makes use of the Peukert` law to change actual current into standard current, and performs integration over time to estimate the current SOC. This method works very accurately for Lithium Ion batteries (LIBs) because there are no significant side reactions during normal operation [29]. Since the main focus of this paper is the impact of integrating large number of EVs on the steady state system loading and voltages, the dynamics of the power electronics are not considered in the simulation.

In the proposed controller, the EV charging algorithm aims at charging the EV without violating the voltage standards of the grid. This will reduce feeder losses and avoid overloads [6]. For a given distribution transformer, the load consists of both controllable and non-controllable loads. By managing the loading level using the controllable load, the voltage profile of the system can be improved due to the direct relation between them. Also, the controller will sense any load change in the system through the voltage at the point of connection since any load change will affect the current flowing in the system and 
the voltage drop across the feeders. In this paper, it is assumed that the controllable loads are represented by the EVs only. The proposed controller is based on fuzzy logic (FL) as depicted in Fig. 4. The FL is a multivalued logic where the variable can belong to many membership functions at the same time. It has the capability to handle the uncertainties that might arise in the system through simple IF-THEN conditioning rules, hence eliminating the need for developing complex mathematical models. Fuzzy logic is used in that work because it can be designed without the need for training data, as long as we know the domain we are modelling and its reaction or rules. Also, fuzzy logic has the advantage of its interpretability and simplicity since it allows modelling using near natural language rules. Since in distribution systems, there are some voltage standards (0.95-1.05 p.u) that should be followed, the distribution system is radial which gives an idea about the voltages at the different buses, and the EV battery SOC has a range to work on (0-100\%), it is appropriate to use a controller based on fuzzy logic to handle the different circumstances that might arise in real systems since it can provide adaptive control within the assigned boundaries of membership functions.

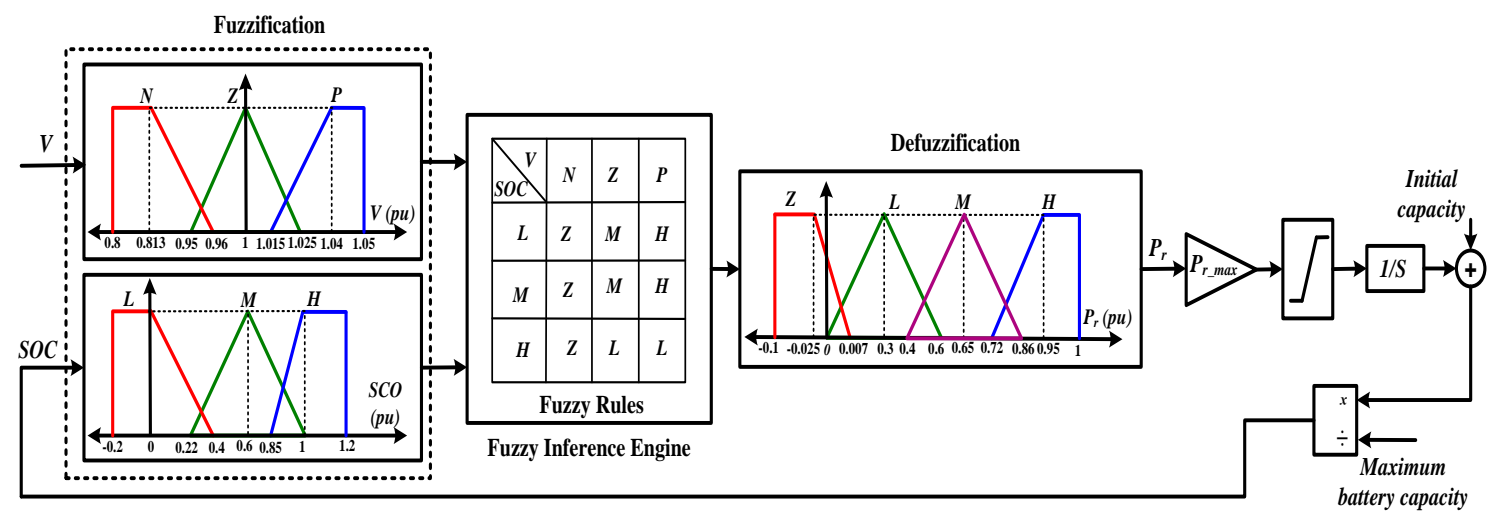

Fig. 4: controller block diagram

The proposed FL controller represents a relationship between the EV charging rate $\left(P_{r}\right)$, the voltage at the point of charge (POC) ( $V$ ) and the state of charge (SOC) of the EV's battery connected to the same point. The inputs to the controller are $V$ and SOC while the output is $P_{r}$. All the control signals (inputs and output) are in per unit. The crisp output $P_{r}$ from FL controller is multiplied by the base charging rate $\left(P_{r_{-} \max }\right)$ to obtain the actual charging rate in $\mathrm{kW}$. The charging rates are chosen based on the IEC-61851 
standard [30] where there is a minimum (30\% of the rated value) and maximum charging (100\% of the rated value) ranges to work on. A saturation limits are introduced in the controller in order to ensure unidirectional power flow under any circumstances. An integrator is used to accumulate the energy and add it to the initial battery capacity to approximately estimate the current $S O C$. The output of the controller is continuous as long as the state of charge $S O C_{i}<S O C_{\max }$ (maximum SOC) and there is no voltage violation (the voltage is higher than 0.95 ). The fuzzy inference system is designed to avoid voltage violation and ensure fair charging among the different EVs connected at different houses.

Fairness is an important factor during the charging of the EVs. As described in [17], it means that "the contribution of each EV to cope with voltage standards should be decided such that the charging of one EV does not go greatly faster than another EV based on their locations in the network". That is, it is not appropriate that EVs connected to downstream, i.e. lower voltage buses, suffer from much lower regulated charging rates than those connected to upstream, i.e. higher voltage buses. This factor can be considered in the control design by using a charging rate function that is not excessively sensitive to the voltage level. Only when the voltage is considerably high, the charging rate should increase. This is done by expanding the fuzzification range of the voltage represented by the Zero $(Z)$ membership function to be from 0.95 to 1.025 , as described in Fig. 4 . When the voltage is pretty high, the Positive $(P)$ membership function is used to indicate high voltage. If the voltage deteriorates below 0.95 , the Negative (N) membership function is assigned.

Another factor which should contribute to the charging rate decision is the EV's SOC. It is desirable that EVs that have a lower SOC to be allowed to charge at a higher charging rate and as the SOC increases, the charging rate should decrease slowly. This helps to increase the battery life time by reducing the charging rate significantly when the battery is near the maximum capacity. This is considered in the proposed controller by dividing the SOC universe of discourse into three membership function, as shown in Fig 4. If the SOC is less than 40\%, the Low $(L)$ membership is assigned to it and if 
it is higher than $85 \%$, the High $(H)$ membership function is used. In between, the Medium $(M)$ membership function will be specified. The fuzzy output (charging rate) is defuzziffied based on Mamdani technique [10] considering the center of gravity method using four membership function. The Zero $(Z)$ membership will be used to stop the charging in the case of any voltage violation. The low $(L)$ membership function is introduced to reduce the charging rate if the battery is near fully charging to protect the battery and increase its life time. The high $(H)$ membership function will be considered if there is no voltage violations and the SOC is very low while the medium $(M)$ membership function will be used in all the other cases. These assignments are indicated by the rule table shown in Fig. 4 and the 3-D surface plot in Fig 5. In all cases, linear (triangular and trapezoidal) membership function are used to minimize the computation effort and avoid long processing time.

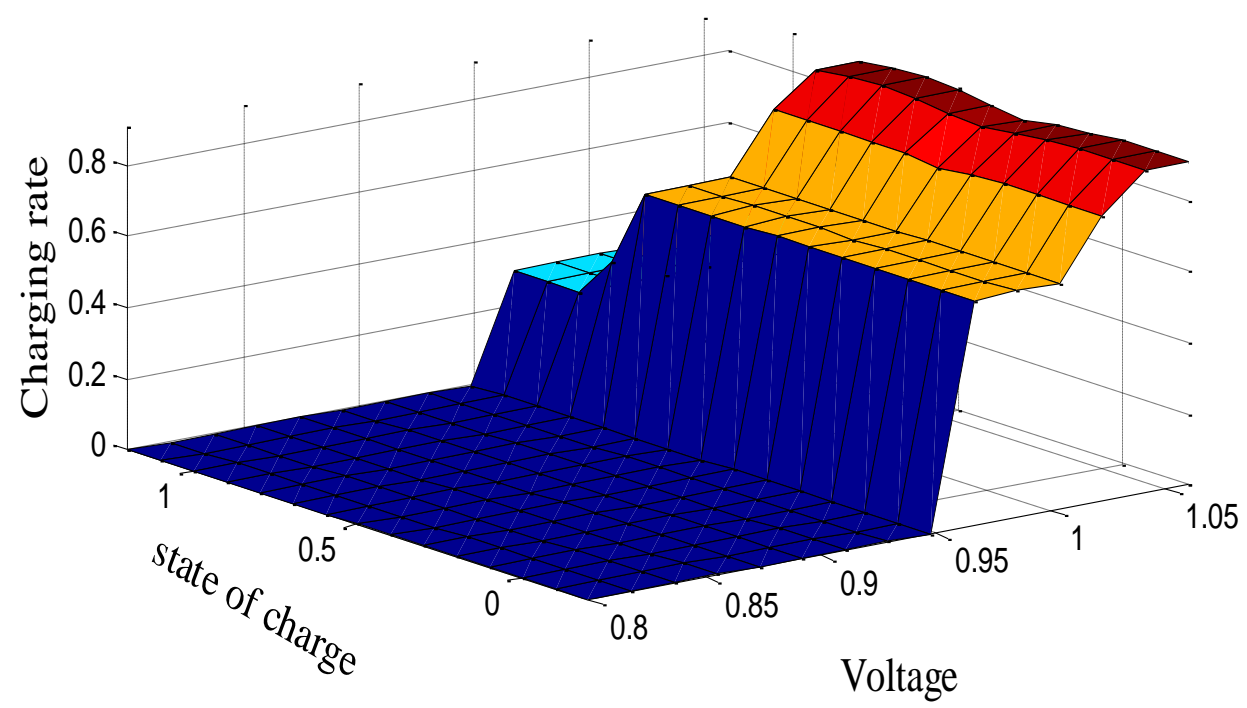

Fig. 5: Rate of charge using the voltage controller logic

\section{Results}

For verification purposes, the distribution network shown in Fig. 1 and 2 driven by the proposed controller was simulated in Matlab environment. The controller was tested under different operating conditions and its performance was compared with selected controllers in literature. The simulation results are presented here. 


\subsection{Performance Evaluation of the Proposed FL controller}

In this section, the system behavior using the proposed FL controller is compared to the case where no control was applied and all the EVs were allowed to charge at the maximum charging rate to complete as fast as possible. The no-control case represents the dump or opportunistic charging to demonstrate the negative impacts of uncontrolled charging of EVs on the distribution system. Also, the proposed fuzzy logic controller performance is compared with the voltage-based droop controller reported in [31] and the exponential autonomous controller behavior reported in [18]. Table 3 shows the voltages at different buses of the system for the four cases, dump charging, using droop controller, using the exponential controller and using the proposed FL controller, respectively. It can be noticed that there are under-voltages at buses $(5,6,7,8,11,12,13,14$ and 15) where the voltage goes below 0.95 pu when dump charging is allowed without control. When the droop or the exponential or the proposed fuzzy controller is applied, the minimum voltage of all buses at the primary side does not go below 0.95 p.u. For the secondary side, it is found that house/EV number 30 at the upstream bus 2 has the highest voltage since it is close to the substation while house/EV number 23 at the downstream bus 6 suffers from the voltage drop since it is far from the substation. Due to the space limitations, most of the results will demonstrate only these extreme cases. Fig. 6 indicates the secondary voltage profile for the upstream EV 30 (Fig. 6(a)) and downstream EV 23 (Fig. 6(b)) using dump charging, the droop, the exponential and the proposed fuzzy controller. It can be observed that the voltage at the downstream point goes below 0.9 p.u, as pointed by the dashed red curve, which is unacceptable. When a controller is applied, the voltage is limited to be higher than or equal to 0.95 pu as described by the solid blue, green and black curves.

The effect of the controlled and uncontrolled charging on the system loading was investigated in Fig. 7. It can be observed that there is a load peaking when all EVs were allowed to charge at the 
maximum rate using dump charging as marked by the dashed red curve. When the droop or the exponential or the proposed fuzzy controller is applied, the load becomes more flat which is desirable. The EV battery SOC over time for EV 30 at bus 2 and EV 23 at bus 6 is shown in Fig. 8. In case of the dump operation, both the upstream and downstream EVs charge at the maximum charging rate and finish as fast as possible at the same time regardless of the system voltage. This was the reason of the severe under-voltage and overloads indicated in Fig. 6 and 7, respectively.

Table 3 Minimum primary voltage in p.u at different Buses

\begin{tabular}{|c|c|c|c|c|}
\hline Node no. & Without controller & Droop control & Exponential controller & Prposed fuzzy controller \\
\hline 2 & 0.9728 & 0.9815 & 0.9803 & 0.9804 \\
\hline 3 & 0.9558 & 0.9703 & 0.9691 & 0.9688 \\
\hline 4 & 0.9548 & 0.9697 & 0.9685 & 0.9681 \\
\hline 5 & 0.9321 & 0.9568 & 0.9549 & 0.9552 \\
\hline 6 & 0.9288 & 0.9537 & 0.9525 & 0.9525 \\
\hline 7 & 0.9274 & 0.9546 & 0.9527 & 0.953 \\
\hline 8 & 0.9267 & 0.9545 & 0.9522 & 0.9529 \\
\hline 9 & 0.972 & 0.9807 & 0.9797 & 0.9797 \\
\hline 10 & 0.9565 & 0.9709 & 0.9685 & 0.9688 \\
\hline 11 & 0.9496 & 0.9665 & 0.9635 & 0.964 \\
\hline 12 & 0.9469 & 0.9648 & 0.9615 & 0.9621 \\
\hline 13 & 0.9456 & 0.9637 & 0.9602 & 0.9611 \\
\hline 14 & 0.9466 & 0.9646 & 0.9613 & 0.9619 \\
\hline 15 & 0.9491 & 0.9662 & 0.9632 & 0.9636 \\
\hline 16 & 0.9508 & 0.9668 & 0.9639 & 0.9646 \\
\hline 17 & 0.9506 & 0.9666 & 0.9637 & 0.9643 \\
\hline 18 & 0.9505 & 0.9666 & 0.9636 & 0.9643 \\
\hline
\end{tabular}



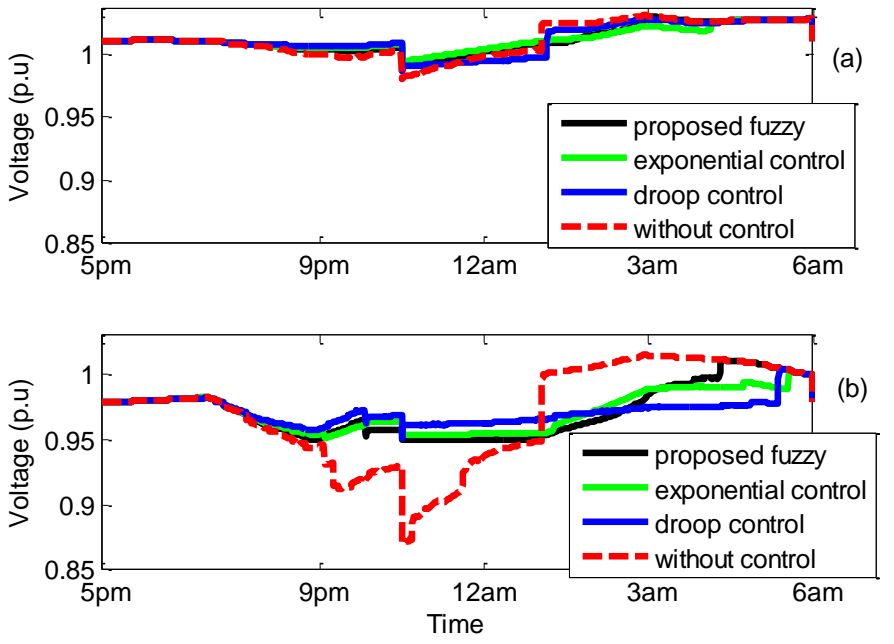

Fig. 6: Secondary voltage profiles with and without control at (a) EV 30 bus 2, (b) EV 23 bus 6
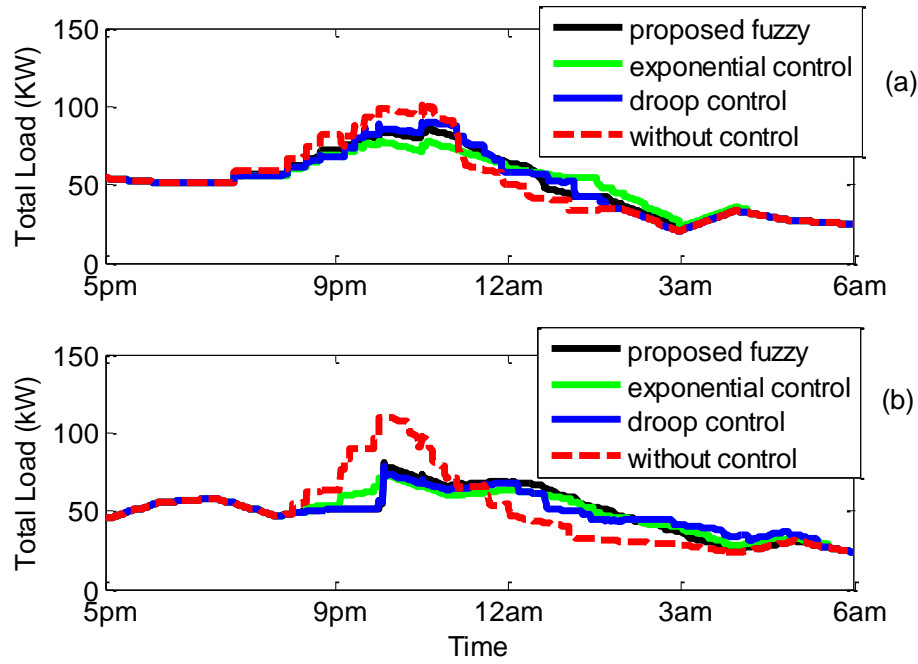

Fig. 7: Total load profile with and without control at (a) phase $\mathrm{C}$ bus 2, (b) phase $\mathrm{C}$ bus 6.
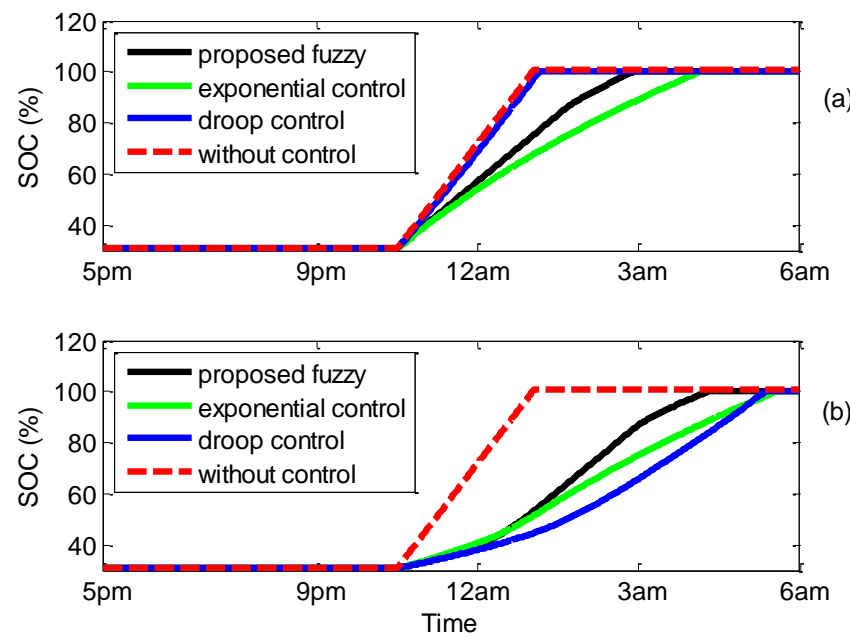

Fig. 8: SOC profiles with and without control at (a) Bus 2, (b) Bus 6. 
On the other hand, when a control is applied, the charging goes slower in order to avoid the negative impacts of EVs on the distribution system. However, all EVs finish charging before 6 a.m. The conventional voltage-based droop control [31] has the disadvantage of lacking the fairness among the different EVs in different locations in the system. It is obvious from the blue curves in Fig. 8 that the droop controller charges the EVs near the substations at a very high rate (almost equal to the dump charging case). However, EVs downstream the system that suffer from the voltage droop across the feeders suffers from much lower charging rate. This comes from the fact that voltage droop controller is very sensitive to the (voltage) location in the network. These observations are also depicted in Table 4 that shows the time to full charge for the different controllers. The proposed fuzzy controller does not suffer from this disadvantage of the droop controller and at the same time outperforms the exponential controller in terms of the speed of charging and the fairness, as depicted in Fig. 8. The time delay of charging between the EVs at the upstream bus 2 and the downstream bus 6 is smaller in the case of the proposed fuzzy controller. This advantage is also demonstrated in Table 4. This difference between the two controllers (the fuzzy and the exponential ones) comes from the fact that the exponential controller only increases the charging by large amount if it is too far from its reference value. This conservative behavior means that if there is a small room in the network for more charging, the exponential controller will not take that opportunity. The proposed fuzzy controller on contrary, increases the charging rate if there is a room for charging as long as it is not violating the standard.

To emphasize the issue of the droop controller and how the problem of location sensitivity can greatly impact the fairness, a comparison is done when the EVs have a very low initial SOC (SOCI) which is assumed here to be $15 \%$. Fig. 9 shows that while EV at the upstream house at bus 2 charges at very high rate, the EV at the downstream house at bus 6 does not manage to fully charge by early morning which is not the case for the proposed fuzzy controller. This shows how the voltage-based droop controller and the location sensitivity issue can cause problems to the EV owners. 

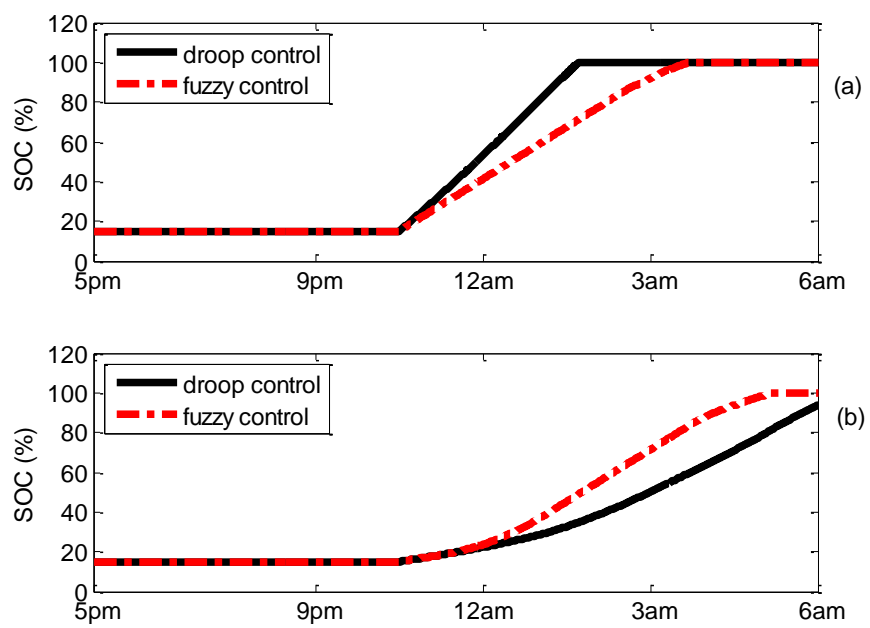

Fig. 9 SOC profiles with and without control at (a) Bus 2, (b) Bus 6 when the EVs has a low SOCI

Table 4 Comparison in terms of time to full charge in hours - droop vs. exponential vs. proposed fuzzy controllers

\begin{tabular}{|c|c|c|c|}
\hline Controller & EV 30 at Bus 2 & EV 23 at Bus 6 & Difference \\
\hline Proportional droop controller & 2.63 & 6.86 & 4.23 \\
\hline Exponential controller & 5.6416 & 7.0583 & 1.42 \\
\hline Fuzzy controller & 4.45 & 5.83 & 1.38 \\
\hline
\end{tabular}

\subsection{Fuzzy Controller Performance under Different Operating Conditions.}

To show the effectiveness of the proposed fuzzy controller, further tests are performed to show its behavior under different operating conditions in the distribution network. In this section, the proposed controller is compared only to the exponential controller which is not sensitive to the location. First, the robustness of the proposed control scheme with respect to varying levels of EV penetrations is assessed. Table 5 shows a comparison in terms of the time needed to fully charge the EVs at buses 2 and 6 . The charging times at upstream (EV 30 at bus 2) and downstream (EV 23 at bus 5) as well as the average charging times of all EVs connected to buses 2 and 6 are analyzed for EV penetration levels of $40 \%$, $50 \%$, and $60 \%$. The results demonstrate reasonable tolerance of this control scheme to different levels of EV penetrations up to $60 \%$. If the penetration depth exceeds this value, EV at house 23 at bus 5 will not be able to fully charge before 6 am which means that there is no enough room in this system under study for penetration depths above $60 \%$. It worth mentioning that the maximum penetration depth of EVs using 
the autonomous exponential control reported in [18] was 50\%. This means that the proposed fuzzy can accommodate extra $10 \%$ of EVs (equivalent to $102 \mathrm{EV}$ ) which is highly desirable. In addition, when the penetration level is less, in the case of $40 \%$, the proposed fuzzy controller shows much faster charging compared with the exponential one, as described in Table 6.

Table 5 Comparison in terms of time to full charge (in hours)

\begin{tabular}{|c|c|c|c|c|}
\hline Penetration Level (\%) & EV 30 at Bus 2 & Mean Bus 2 & EV 23 at Bus 6 & Mean Bus 6 \\
\hline 40 & 3.2 & 2.3444 & 3.842 & 2.8128 \\
\hline 50 & 4.45 & 3.6356 & 5.83 & 4.3833 \\
\hline 60 & 5.558 & 4.9108 & 7.5 & 5.8636 \\
\hline
\end{tabular}

Table 6 Comparison in terms of time to full charge (in Hours) in case of $40 \%$ penetration depth of EVs

\begin{tabular}{|c|c|c|c|c|}
\hline EV Level (40 \%) & EV 30 at Bus 2 & Mean Bus 2 & EV 23 at Bus 6 & Mean Bus 6 \\
\hline Fuzzy & 3.2 & 2.3444 & 3.842 & 2.8128 \\
\hline Exponential & 5.175 & 3.8703 & 5.66 & 4.0078 \\
\hline
\end{tabular}

Another important test is the controller performance in the presence of voltage control units. It is the utility's responsibility to keep the customer voltage within specified tolerances by installing voltage regulating units. The performance of proposed fuzzy controller is studied in the presence of such units. In this paper, shunt capacitors are considered to be connected to the downstream bus 5 which is chosen since the support at that point will help buses 6,7 , and 8 which suffer from low voltages as mentioned before in Table 3. The total available capacitors capacity is assumed to be 1 MVAR. The capacitor variation step is equivalent to 0.1 MVAR, which causes an increase/decrease of about 0.007 per unit voltage. The capacitor bank is assumed to be controlled by an autonomous feedback controller whose voltage set point is $0.99 \mathrm{pu}$ and bandwidth is $0.007 \mathrm{pu}$. Fig. 10 shows the improvement in the voltage profile at the points of charging for EVs 30 and 23 at buses 2 and 6, respectively. The corresponding capacitor steps that used to improve the voltage is given in Fig. 11. Since the voltage has improved at the downstream buses, the fuzzy controller will increase the charging rates accordingly. Fig. 12. Shows a comparison of the average 
SOC of all EVs connected to the downstream bus 6 and upstream bus 2. The comparison shows that All EVs charge almost at the same high charging rate which is greatly desirable and fair.

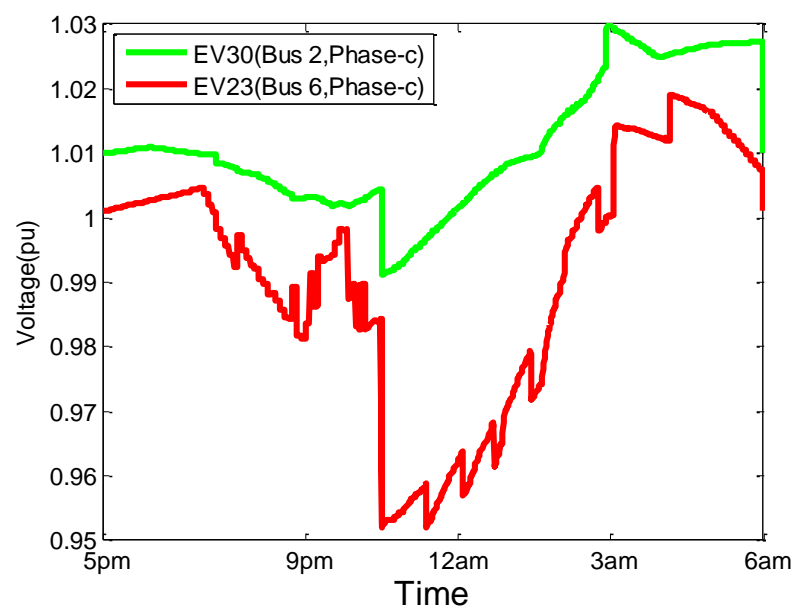

Fig. 10: Voltage profiles for POC of EVs 30 and 23 at buses 2 and 6 in case of SC at bus 5

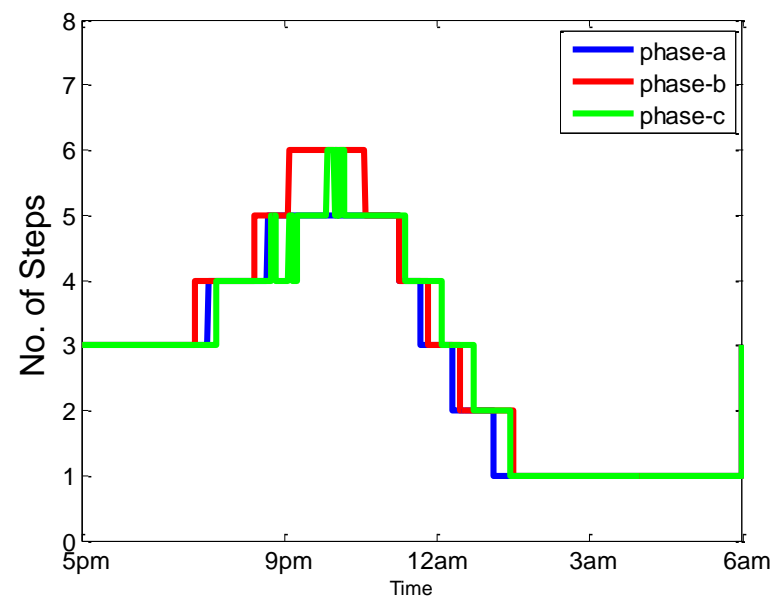

Fig. 11 Shunt Capacitor steps at bus 5

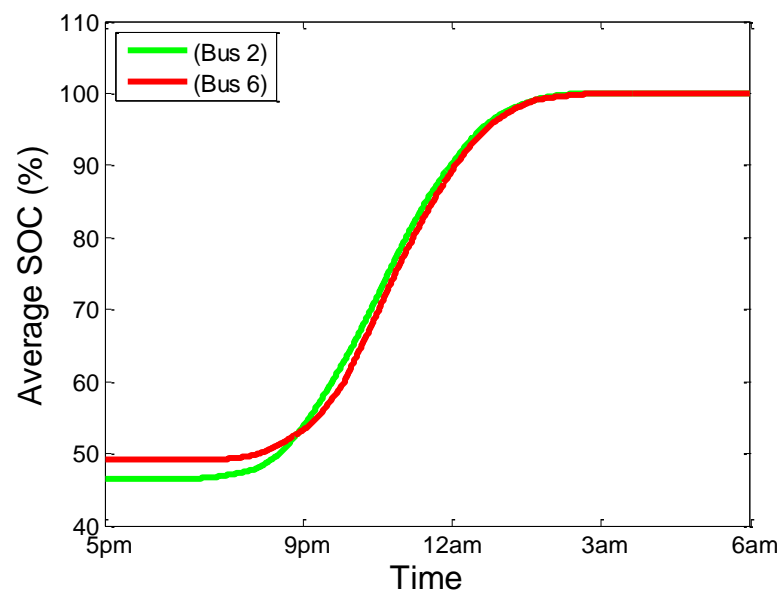

Fig. 12 Average SOC profiles at bus 2 and bus 6 in case of SC at bus 5 
The influence of the proposed fuzzy controller with respect to expected system reconfiguration is investigated as well. This is studied for simple and severe reconfiguration events. The simple reconfiguration is carried out by removing one representative bus from the primary distribution system to emulate switching that bus to an adjacent feeder during a reconfiguration event. For the severe reconfiguration event, multiple buses reconfiguration is achieved by removing buses 10-18 simultaneously (which are almost half of the system). Table 7 shows the full charge time of the EV under different reconfiguration tests. It can be seen that the reconfiguration has not a great effect on the upstream bus since it is already charging fast. However, it decreases the time to full charge EV 23 at bus 6 from 5.83 in the normal conditions to 5.48 and 5.27 in case of simple and severe reconfiguration, respectively. This happens because dropping one or more buses results in controllable and uncontrollable load reduction. This reduction in load causes increase in the charging rate of all the EVs connected to the system but the EVs that suffer from low voltages are the ones which take the advantage of the increased charging which is desirable. A similar conclusion can be reached for the case of light loading conditions. This test was done by reducing all the uncontrollable loads by $20 \%$ of its original value. The results for that test were also presented in Table 7 where it can be noticed that the time to fully charge the EVs has been reduced. This is also can be observed from the voltage improvements in Fig. 13 and the average SOC profiles in Fig.14.

Table 7 Comparison in terms of time to full charge (in hours) in case of reconfiguration tests

\begin{tabular}{|c|c|c|c|c|}
\hline Penetration Level (\%) & EV 30 at Bus 2 & Mean Bus 2 & EV 23 at Bus 6 & Mean Bus 6 \\
\hline Normal case & 4.4 & 3.6356 & 5.83 & 4.3833 \\
\hline Configurating Bus 2 & 4.38 & 3.6264 & 5.48 & 4.21 \\
\hline Configurating Bus 10-18 & 4.34 & 3.5419 & 5.27 & 4 \\
\hline Light Loading & 4.3 & 3.5819 & 5.16 & 3.98 \\
\hline
\end{tabular}




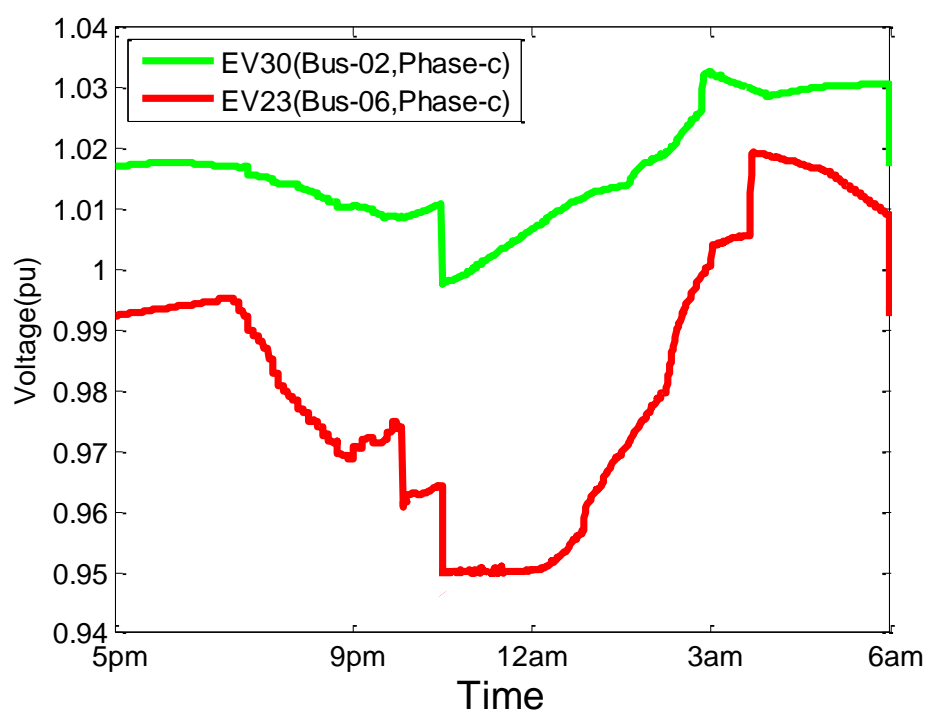

Fig. 13 Voltage profiles for POC of EVs 30 and 23 at buses 2 and 6 in case of light loading

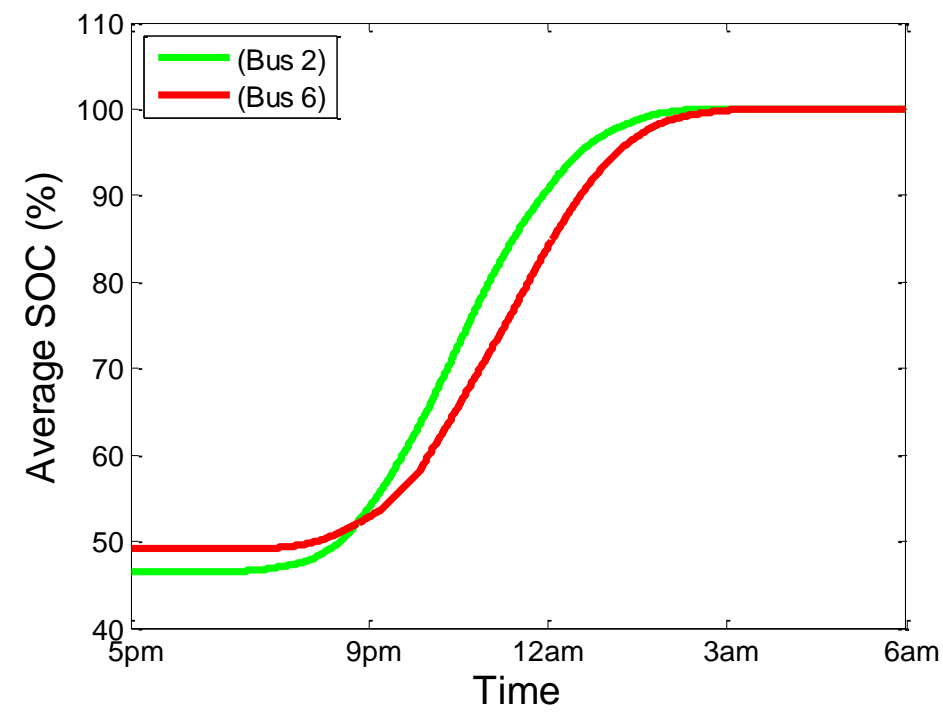

Fig. 14 Average SOC profiles at bus 2 and bus 6 in case of light loading

\subsection{Distributed Generation units Test}

The presence of the distributed generation (DG) will impact the power distribution system operation and control. It is therefore deemed necessary to evaluate the impact of increased DG on the proposed controller performance. Among the different DG technologies, the effect of wind energy is evaluated in this section. Solar energy is not investigated due to the assumption that the EV are charging according to the time of use tariff where the EVs are charging at homes from $6 \mathrm{pm}$ to $6 \mathrm{am}$. 
Fig. 15 shows the wind energy profile for a sample day where the wind data is actual data from ERCOT [32]. For this test a wind turbine is installed either at the downstream house at bus 6, which suffers from low voltage, or at the upstream house at bus 2 which has the highest primary voltage in the system. The test is performed to show the performance of the controller while the house is feeding itself from a renewable energy resource. Fig. 16 shows the secondary voltage profiles when no wind turbine (WT) is used and when the wind turbines are located at the upstream and downstream houses one at a time. The figure indicates that when the wind turbine is located at the downstream house, it will improve the voltage profile at the point of charging (POC) of house 23 as shown by the red dashed curve in Fig. 16(b). However, it will have no effect on the voltage profile at the POC of the upstream house 30 since the wind power is small and it will have a minor effect on the other houses. Therefore, Fig. 16(a) shows almost the same voltage profile at house 30 as the normal case with no wind turbine installed (the black and the red dashed curves). Similarly, when the wind turbine is installed at the upstream house 30 at bus 2, it improves the voltage at that house as shown by the green curve in Fig. 16(a) but it will not affect the downstream house 23 in Fig. 16(b) where the same voltage profile at house 23 as the normal case with no wind turbine installed (the black and the green curves).

Fig. 17 shows the corresponding charging profiles for the three different cases. It can be seen that when the wind turbine is installed at the downstream house 23 , the charging rate increases and the charging process finishes faster as shown in Fig. 17(b). This occurs due to the improvement in the voltage. However, when the wind turbine is installed at the upstream house 30, it will increase the charging rate by a small amount as shown in Fig. 17(a). This happens because this house is already connected to a POC with high voltage and it is already charging with a high charging rate. Table 8 shows the effect of installing a small wind turbine on the time to full charge the EVs. The interesting result in that table is that when a downstream house has its own generation, it can charge with almost the same charging rate as the upstream house near the substation. This is seen for the case when the wind turbine is 
installed at the downstream house at bus 6 where the difference in the time to full charge the EV between the upstream and downstream house is .05 hour (about 3 minutes) which is highly desirable. This is also obvious from the SOC profiles in Fig. 18.

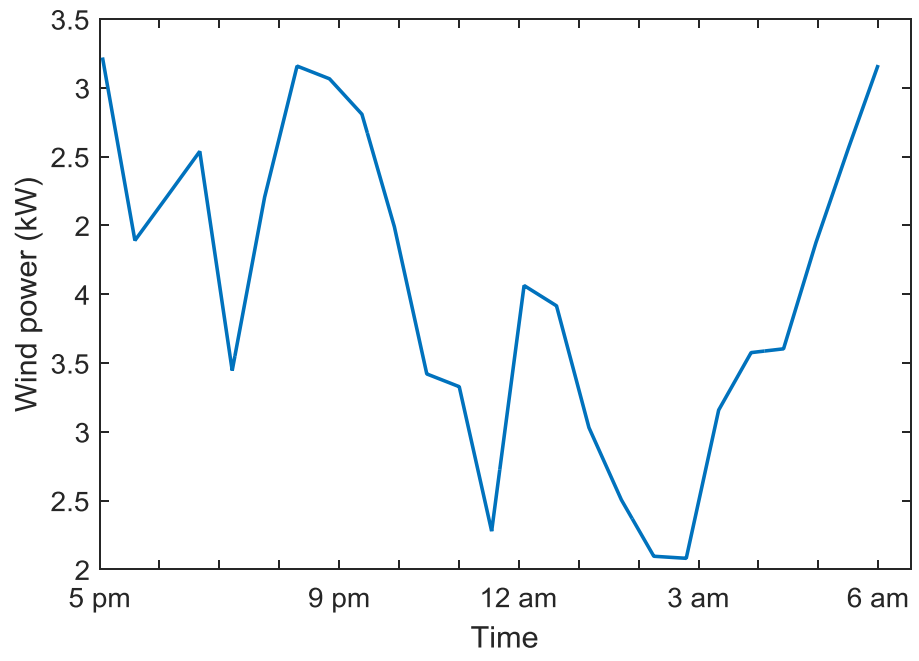

Fig. 15 Wind power for a sample day in $\mathrm{kW}$
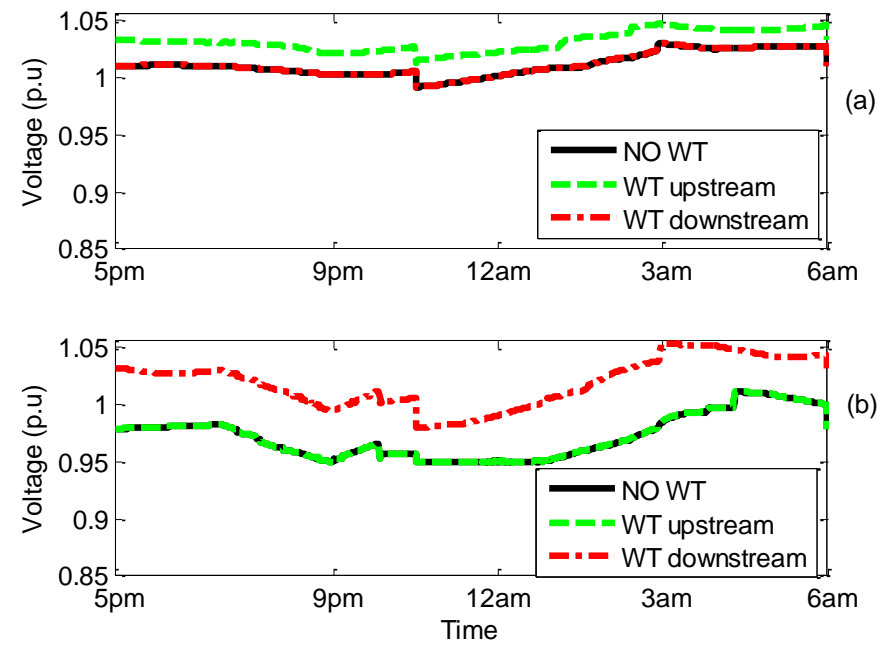

Fig. 16 Secondary voltage profiles in case of no wind turbine, wind turbine at house 30 bus 2 and wind turbine at house 23 bus 6 (a) EV 30 bus 2, (b) EV 23 bus 6 

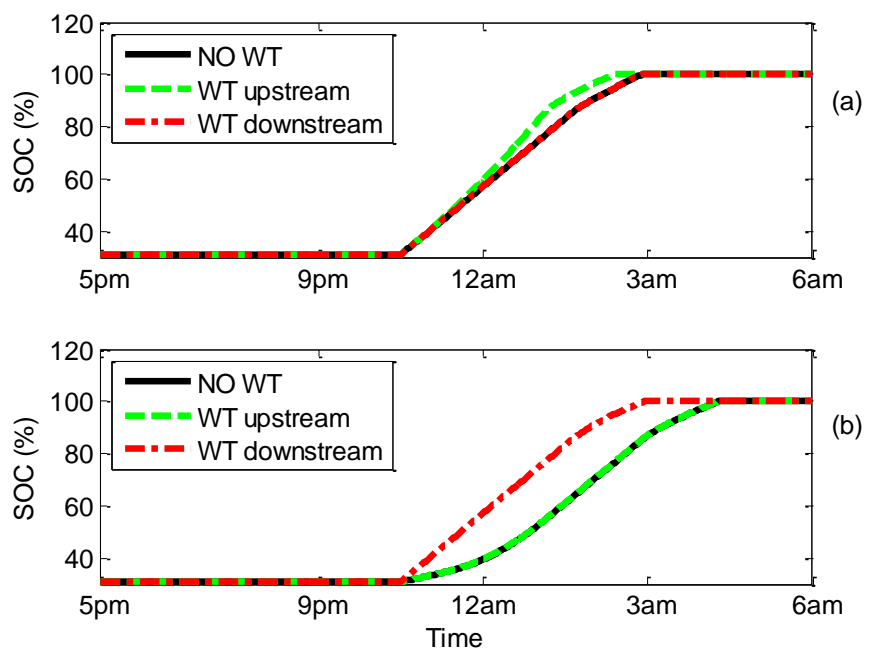

Fig. 17 SOC profiles in case of no wind turbine, wind turbine at house 30 bus 2 and wind turbine at house 23 bus 6 (a) EV 30 bus 2, (b) EV 23 bus 6

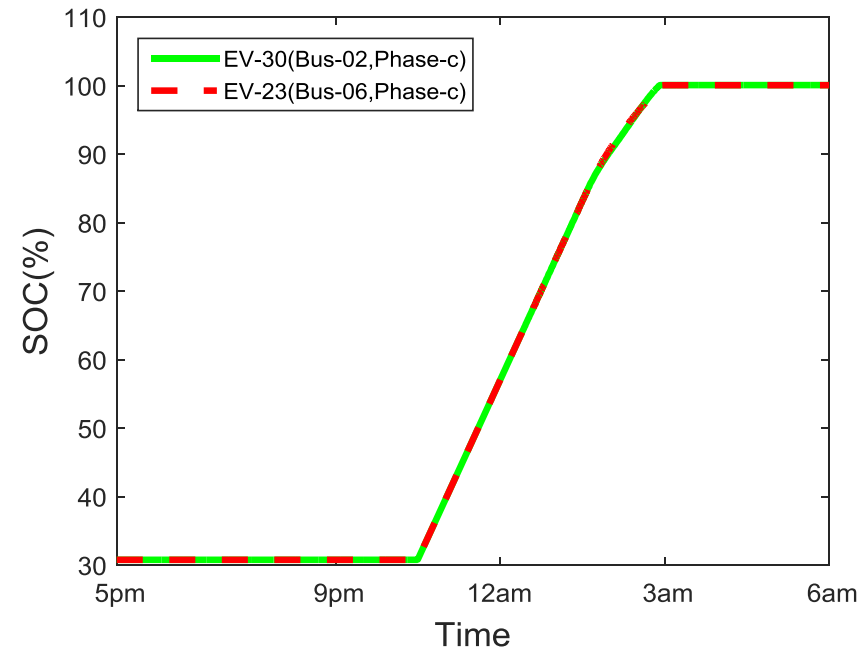

Fig. 18 SOC profiles in case of wind turbine at house 23 bus 6

Table 8 Comparison in terms of time to full charge in hours in case of installing a small wind turbine

\begin{tabular}{|c|c|c|c|}
\hline EVs & EV 30 at Bus 2 & EV 23 at Bus 6 & Difference \\
\hline Normal case No WT & 4.4 & 5.8 & 1.4 \\
\hline WT at house 30 Bus 2 & 3.9 & 5.79 & 1.89 \\
\hline WT at house 23 Bus 6 & 4.39 & 4.44 & 0.05 \\
\hline
\end{tabular}

\subsection{Controller sensitivity to errors in SOC estimation}

In this section, the performance of the proposed fuzzy controller is tested under a range of random errors in SOC estimation. This test is made to show how sensitive is the controller to errors in SOC estimation. 
The controller performance will be tested under three different errors, with maximum error of $1 \%, 3 \%$ and 5\% in SOC estimation [29], [33]. These cases are compared to the accurate case when there is no errors. Fig. 19 shows the voltage profile at phase $\mathrm{C}$ bus 2 and 6 . It is obvious that there is almost no effect on the system voltage due to SOC estimation error. Fig. 20 shows the average SOC over time for all EVs at bus 2 and 6. It confirms that the controller was not affected by errors in SOC estimation. This happens because the SOC error is coming from measurement noise which is small and can be positive and negative which makes the accumulated error over time too small as well. Hence, it will not have much impact on the controller performance.
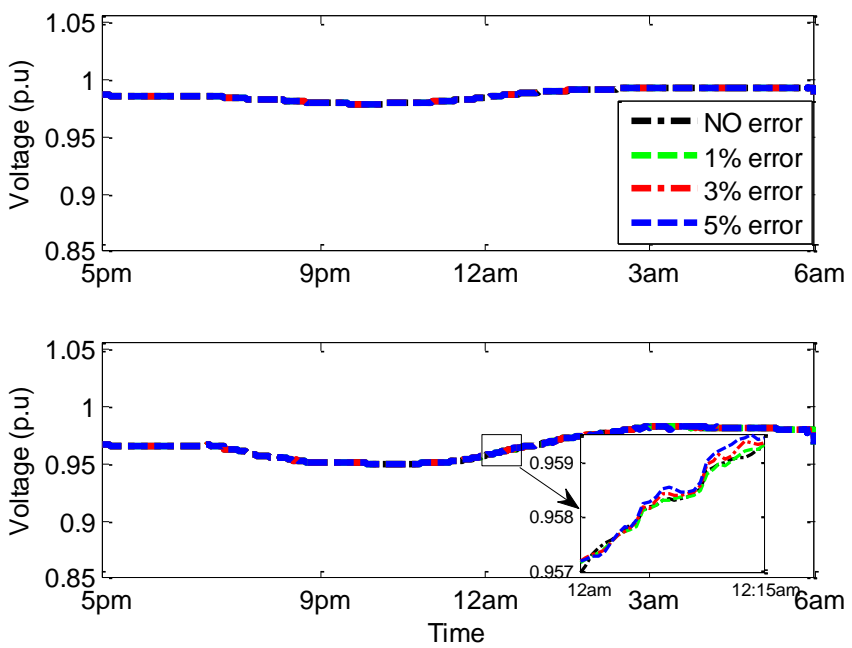

Fig. 19 Voltage profiles for phase $\mathrm{C}$ at (a) bus 2, (b) bus 6
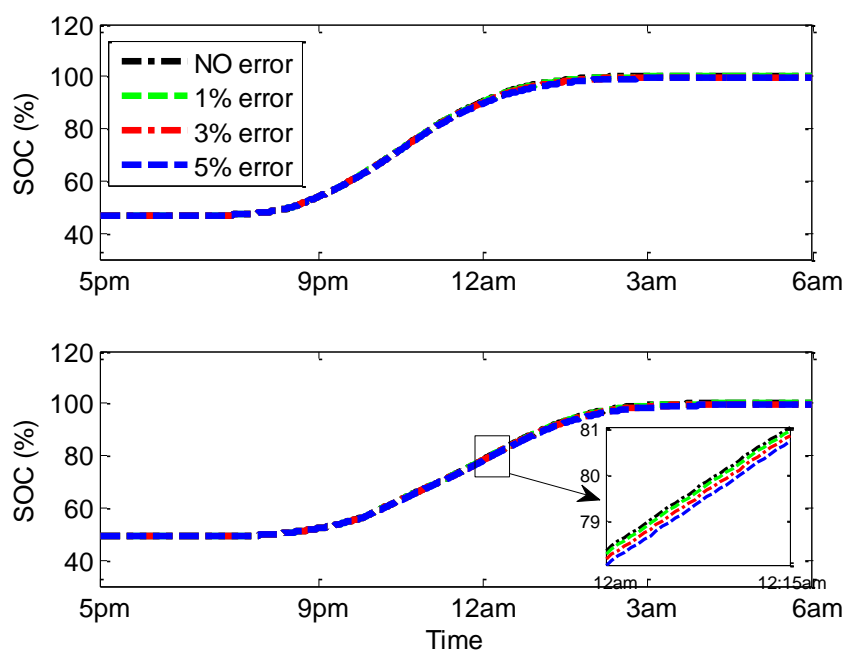

Fig. 20 Average SOC profiles at (a) bus 2, (b) bus 6 


\section{Conclusion}

This paper presented an effective and practical communication-free EV charging controller. The control technique uses fuzzy logic to ensure fairness among the different EV's connected at different parts of the system as well as commitment with the voltage constraint regulation in the distribution network. Several practical considerations and operating conditions in the distribution network were addressed, including different loading conditions and system reconfiguration. The sensitivity of the controller to errors is the state of charge estimation is also tested. The simulation results show the robustness of the controller under different conditions varying from light loading to normal loading conditions and from simple to significant reconfiguration. Moreover, the outcomes ensure the effectiveness of the controller in the presence of voltage control units connected to the system such as capacitor banks. Also, the controller performed well in the presence of the distributed generation units such as wind turbines.

\section{Acknowledgments}

Part of this work was supported by the office of Naval Research and the US Department of Energy. The authors are with the Energy System Research Laboratory, ECE Department. Florida International University, Miami, FL, 33174 USA. (E-mail: mohammed@fiu.edu). 


\section{References}

[1] A. Dubey and S. Santoso, "Electric Vehicle Charging on Residential Distribution Systems: Impacts and Mitigations," IEEE Access, vol. 3, pp. 1871-1893, 2015.

[2] M. Sorrentino, G. Rizzo, and L. Sorrentino, "A study aimed at assessing the potential impact of vehicle electrification on grid infrastructure and road-traffic green house emissions," Appl. Energy, vol. 120, pp. 31-40, May 2014.

[3] F. Millo, L. Rolando, R. Fuso, and F. Mallamo, "Real CO2 emissions benefits and end user's operating costs of a plug-in Hybrid Electric Vehicle,” Appl. Energy, vol. 114, pp. 563-571, Feb. 2014.

[4] D. Dallinger, S. Gerda, and M. Wietschel, "Integration of intermittent renewable power supply using grid-connected vehicles - A 2030 case study for California and Germany," Appl. Energy, vol. 104, pp. 666-682, Apr. 2013.

[5] M. A. Masoum, P. S. Moses, and S. Hajforoosh, "Distribution transformer stress in smart grid with coordinated charging of Plug-In Electric Vehicles," in Innovative Smart Grid Technologies (ISGT), 2012 IEEE PES, 2012, pp. 1-8.

[6] E. Sortomme, M. M. Hindi, S. D. J. MacPherson, and S. S. Venkata, "Coordinated Charging of Plug-In Hybrid Electric Vehicles to Minimize Distribution System Losses,” IEEE Trans. Smart Grid, vol. 2, no. 1, pp. 198-205, Mar. 2011.

[7] P. Richardson, D. Flynn, and A. Keane, "Impact assessment of varying penetrations of electric vehicles on low voltage distribution systems," in Power and Energy Society General Meeting, 2010 IEEE, 2010, pp. 1-6.

[8] J. A. Peças Lopes, S. A. Polenz, C. L. Moreira, and R. Cherkaoui, "Identification of control and management strategies for LV unbalanced microgrids with plugged-in electric vehicles,” Electr. Power Syst. Res., vol. 80, no. 8, pp. 898-906, Aug. 2010.

[9] H. Liu, Z. Hu, Y. Song, J. Wang, and X. Xie, "Vehicle-to-Grid Control for Supplementary Frequency Regulation Considering Charging Demands," IEEE Trans. Power Syst., vol. 30, no. 6, pp. 3110-3119, Nov. 2015.

[10] P. Zhang, K. Qian, C. Zhou, B. G. Stewart, and D. M. Hepburn, "A Methodology for Optimization of Power Systems Demand Due to Electric Vehicle Charging Load,” IEEE Trans. Power Syst., vol. 27, no. 3, pp. 1628-1636, Aug. 2012.

[11] M. Singh, P. Kumar, and I. Kar, "Implementation of Vehicle to Grid Infrastructure Using Fuzzy Logic Controller," IEEE Trans. Smart Grid, vol. 3, no. 1, pp. 565-577, Mar. 2012.

[12] M. Singh, K. Thirugnanam, P. Kumar, and I. Kar, "Real-Time Coordination of Electric Vehicles to Support the Grid at the Distribution Substation Level," IEEE Syst. J., vol. 9, no. 3, pp. 1000-1010, Sep. 2015.

[13] C. Ahn, C.-T. Li, and H. Peng, "Decentralized charging algorithm for electrified vehicles connected to smart grid," in American Control Conference (ACC), 2011, 2011, pp. 3924-3929.

[14] W. Su and M.-Y. Chow, "Computational intelligence-based energy management for a large-scale PHEV/PEV enabled municipal parking deck," Appl. Energy, vol. 96, pp. 171-182, Aug. 2012.

[15] L. Gan, U. Topcu, and S. H. Low, "Optimal decentralized protocol for electric vehicle charging," IEEE Trans. Power Syst., vol. 28, no. 2, pp. 940-951, May 2013.

[16] A. Mohamed, M. Elshaer, and O. Mohammed, "Control enhancement of power conditioning units for high quality PV systems," Electr. Power Syst. Res., vol. 90, pp. 30-41, Sep. 2012.

[17] M. Elshaer, A. Mohamed, and O. A. Mohammed, "Smart optimal control of DC-DC boost converter for intelligent PV systems," in 2011 16th International Conference on Intelligent System Applications to Power Systems, 2011, pp. 1-6.

[18] A. Arancibia and K. Strunz, "Autonomous control of electric vehicles in grid-connected and islanded modes," in Innovative Smart Grid Technologies (ISGT Europe), 2012 3rd IEEE PES International Conference and Exhibition on, 2012, pp. 1-7.

[19] T. Sansawatt, L. F. Ochoa, and G. P. Harrison, "Smart Decentralized Control of DG for Voltage and Thermal Constraint Management," IEEE Trans. Power Syst., vol. 27, no. 3, pp. 1637-1645, Aug. 2012.

[20] A. T. Al-Awami and E. Sortomme, "Electric vehicle charging modulation using voltage feedback control," in Power and Energy Society General Meeting (PES), 2013 IEEE, 2013, pp. 1-5.

[21] G. M. Asim Akhtar, A. T. Al-Awami, E. Sortomme, M. A. Abido, and M. W. Ahmed, "Autonomous electric vehicle charging management over real time digital simulator," in PES General Meeting| Conference \& Exposition, 2014 IEEE, 2014, pp. 1-5.

[22] A. T. Al-Awami, E. Sortomme, G. M. A. Akhtar, and S. Faddel, "A Voltage-Based Controller for an Electric-Vehicle Charger," IEEE Trans. Veh. Technol., vol. 65, no. 6, pp. 4185-4196, Jun. 2016.

[23] S. Faddel, A. T. Al-Awami, and M. A. Abido, "Real time digital simulation of voltage-based controller for electric vehicle charging," in 2016 Clemson University Power Systems Conference (PSC), 2016, pp. 1-5.

[24] Cooper Power Systems, Electrical Distribution-System Protection, 3rd ed. Cooper Industries, 1990.

[25] M. A. Zamani, A. Yazdani, and T. S. Sidhu, "A Communication-Assisted Protection Strategy for Inverter-Based Medium-Voltage Microgrids," IEEE Trans. Smart Grid, vol. 3, no. 4, pp. 2088-2099, Dec. 2012.

[26] F. Lambert, Secondary Distribution Impacts of Residential Electric Vehicle Charging. California Energy Commission, 2000.

[27] Nissan USA, "2013 Nissan LEAF® Electric Car Specifications.” 2013.

[28] E. Sortomme, A. I. Negash, S. S. Venkata, and D. S. Kirschen, "Multistate voltage dependent load model of a charging electric vehicle," in Transportation Electrification Conference and Expo (ITEC), 2012 IEEE, 2012, pp. 1-5.

[29] W. Waag, C. Fleischer, and D. U. Sauer, "Critical review of the methods for monitoring of lithium-ion batteries in electric and hybrid vehicles," J. Power Sources, vol. 258, pp. 321-339, Jul. 2014.

[30] IEC, "IEC 61851-1, Electric Vehicle Conductive Charging System - Part 1: General Requirements. IEC, 2nd ed.," 2010.

[31] F. Geth, N. Leemput, J. Van Roy, J. Buscher, R. Ponnette, and J. Driesen, "Voltage droop charging of electric vehicles in a residential distribution feeder," in Innovative Smart Grid Technologies (ISGT Europe), 2012 3rd IEEE PES International Conference and Exhibition on, 2012, pp. 1-8.

[32] ERCOT, "Hourly Aggregated Wind Output," http://ercot.com/gridinfo/generation, accessed Feb, 2017. 
[33] Y. Tian, D. Li, J. Tian, and B. Xia, "State of charge estimation of lithium-ion batteries using an optimal adaptive gain nonlinear observer," Electrochimica Acta, vol. 225, pp. 225-234, Jan. 2017.

\section{List of Figures:}

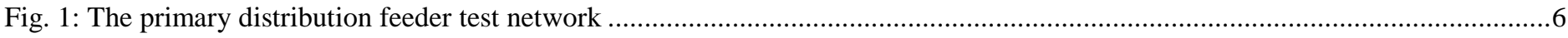

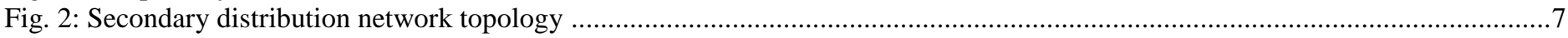

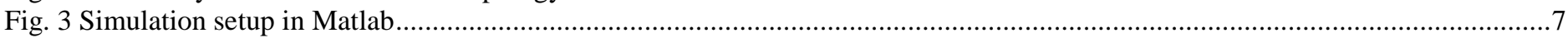

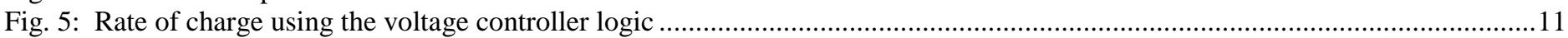

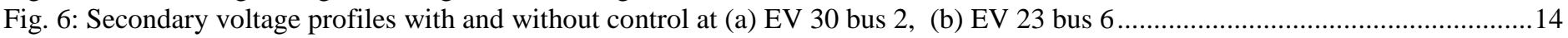

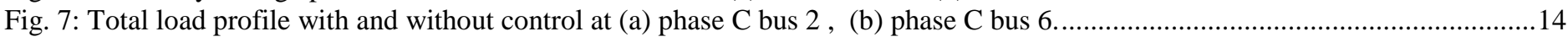

Fig. 8: SOC profiles with and without control at (a) Bus 2 , (b) Bus 6 ....................................................................................14

Fig. 9 SOC profiles with and without control at (a) Bus 2, (b) Bus 6 when the EVs has a low SOCI ............................................16

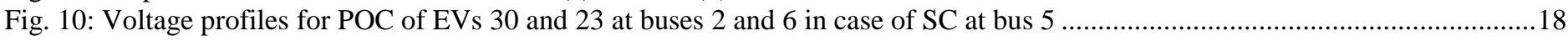

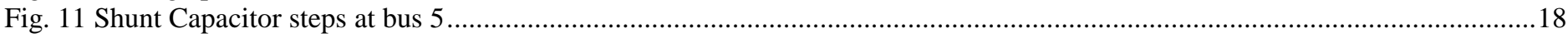

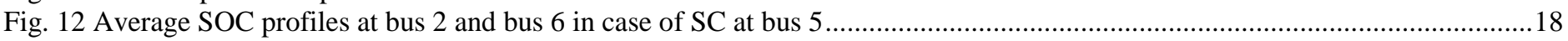

Fig. 13 Voltage profiles for POC of EVs 30 and 23 at buses 2 and 6 in case of light loading ....................................................20

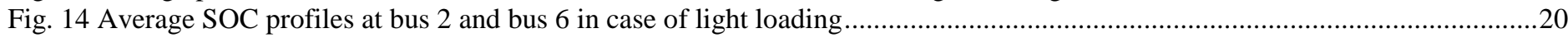

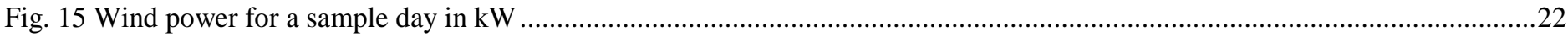

Fig. 16 Secondary voltage profiles in case of no wind turbine, wind turbine at house 30 bus 2 and wind turbine at house 23 bus $6 \ldots . .22$

Fig. 17 SOC profiles in case of no wind turbine, wind turbine at house 30 bus 2 and wind turbine at house 23 bus $6 \ldots \ldots \ldots \ldots \ldots \ldots \ldots \ldots . . . .23$

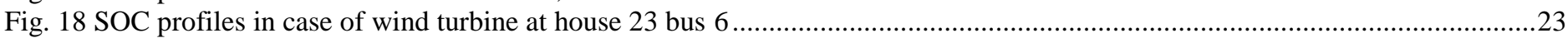

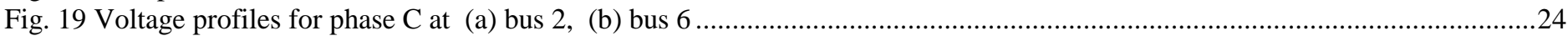

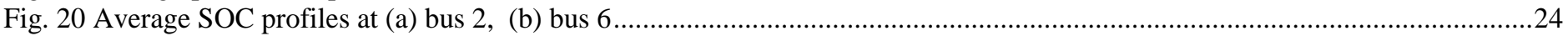

\section{List of Tables:}

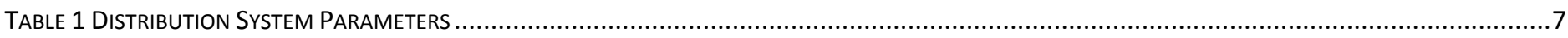

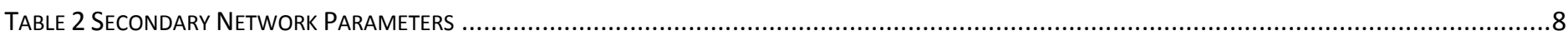

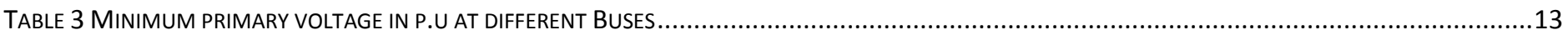

TABLE 4 COMPARISON IN TERMS OF TIME TO FULL CHARGE IN HOURS - DROOP VS. EXPONENTIAL VS. PROPOSED FUZZY CONTROLLERS................................16

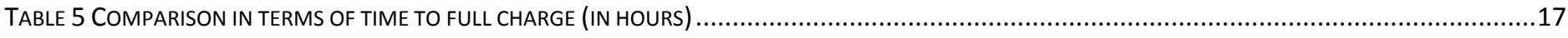

TABLE 6 COMPARISON IN TERMS OF TIME TO FULL CHARGE (IN HOURS) IN CASE OF $40 \%$ PENETRATION DEPTH OF EVS.............................................17

TABLE 7 COMPARISON IN TERMS OF TIME TO FULL CHARGE (IN HOURS) IN CASE OF RECONFIGURATION TESTS .......................................................19

TABLE 8 COMPARISON IN TERMS OF TIME TO FULL CHARGE IN HOURS IN CASE OF INSTALLING A SMALL WIND TURBINE ..............................................23 